\title{
Correction to: A novel histone deacetylase inhibitor, CG200745, potentiates anticancer effect of docetaxel in prostate cancer via decreasing $\mathrm{MCl}-1$ and $\mathrm{BCl}_{-\mathrm{xL}}$
}

\author{
Jung Jin Hwang ${ }^{1,2} \cdot$ Yong Sook Kim ${ }^{2} \cdot$ Taelim Kim $^{2} \cdot$ Mi Joung Kim ${ }^{2} \cdot$ In Gab Jeong ${ }^{3}$. Je-Hwan Lee ${ }^{4}$. \\ Jene $\mathrm{Choi}^{5}$. Sejin Jang ${ }^{5}$. Seonggu $\mathrm{Ro}^{6}$. Choung-Soo Kim ${ }^{3}$
}

Published online: 2 April 2019

(C) Springer Science+Business Media, LLC, part of Springer Nature 2019

\section{Correction to: Invest New Drugs (2012) 30:1434-1442 \\ https://doi.org/10.1007/s10637-011-9718-1}

The blots of control and docetaxel for caspase-9, caspase-3, caspase- $8, \mathrm{Bcl}_{-\mathrm{XL}}$, and tubulin in the Figure $4 \mathrm{f}$ were reused from Figure 4 of our previous paper published in Journal of Urology in 2010 (https://doi.org/10.1016/j.juro.2010.07.035).

Publisher's note Springer Nature remains neutral with regard to jurisdictional claims in published maps and institutional affiliations.

The online version of the original article can be found at https://doi.org/ 10.1007/s10637-011-9718-1

Choung-Soo Kim

cskim@amc.seoul.kr

1 Department of Convergence Medicine, University of Ulsan College of Medicine, Asan Medical Center, Seoul 05505, South Korea

2 Institute for Innovative Cancer Research, University of Ulsan College of Medicine, Asan Medical Center, Seoul 05505, South Korea

3 Department of Urology, University of Ulsan College of Medicine, Asan Medical Center, 88, Olympic-ro 43-gil, Songpa-Gu, Seoul 05505, South Korea

4 Department of Internal Medicine \& Laboratory Medicine, University of Ulsan College of Medicine, Asan Medical Center, Seoul 05505, South Korea

5 Department of Pathology, University of Ulsan College of Medicine, Asan Medical Center, Seoul 05505, South Korea

6 PiMedBio, Inc., Seoul 06367, South Korea 